\title{
The PD catheter dilemma
}

\section{Tom McGregor, MD, FRCSC}

*Department of Surgery, St-Boniface General Hospital, Winnipeg, MB
See related article on page 376 .

Cite as: Can Urol Assoc J 2012;6(5):379. http://dx.doi.org/10.5489/cuaj. 12270

$\mathrm{T}$ his study helps to shed light on a long-standing dilemma in renal transplant surgery: whether to remove the peritoneal dialysis (PD) catheter at the time of transplant surgery or to leave it in place until established renal allograft function down the road. ${ }^{1}$ The potential benefits to removing the PD catheter at the time of surgery are that you eliminate the need for a second procedure, as well as avoid the potential complications fraught with having a PD catheter (e.g., infection, peritonitis) as highlighted in this study. ${ }^{1}$ On the other hand, in the face of delayed graft function (DGF) having PD catheter in place postoperatively leaves the potential to use that catheter for temporizing peritoneal dialysis while waiting for the allograft to recover function. ${ }^{2}$ However, as pointed out in several studies including this one, peritoneal dialysis in the post-transplant setting is also fraught with a high risk of potential complications, including fluid leakage from the incision if the peritoneum is violated during the transplant surgery. ${ }^{3-5}$ Therefore, the overall benefit to leaving a PD catheter in place seems to be minimal, especially in the live-donor population of transplants where the DGF rate is exceedingly low.

In Winnipeg, we have had a very similar experience with our perioperative PD catheter situations; our new policy is to remove PD catheters on all transplant patients. As pointed out by the authors in this study, ${ }^{1}$ in the setting of DGF temporary dialysis can be facilitated by a central catheter which is very easy to place and remove and is associated with a low complication rate. In fact, most transplant recipients already have a central line in place at the time of surgery for central venous pressure monitoring and drug administration, so utilizing this line or switching it over to a dialysis line is very convenient.

Despite the need for future prospective studies, the evidence points to an overall benefit of PD catheter removal at the time of kidney transplantation. This seems to outweigh the benefits of leaving in the PD catheter. Obviously, every patient and clinical scenario is different and there may be situations were this rule does not apply. Warren and colleagues make a strong case for PD catheter removal at the time of surgery. ${ }^{1}$

Competing interests: None declared.

This paper has been peer-reviewed.

\section{References}

1. Warren J, Jones E, Sener A, et al. Should peritoneal dialysis catheters be removed at the time of kidney transplantation? Can Urol Assoc J 2012;6:376-8. http://dx.doi.org/10.5489/cuaj.12112

2. Leichter $\mathrm{HE}$, Salusky IB, Ettenger RB, et al. Experience with renal transplantation in children undergoing peritoneal dialysis (CAPD/CCPD). Am J Kidney Dis 1986;8:181-5.

3. Andreetta B, Verrina E, Sorino $P$, et al. Complications linked to chonic peritoneal dialysis in children after kidney transplantation: experience of the Italian Registry of Pediatric Chronic Peritoneal Dialysis. Perit Dial Int 1996;16:S570-3.

4. Gokal R, Kost S. Peritoneal dialysis immediately post transplantation. Adv Perit Dial 1999;15:112-5.

5. Arbeiter K, Pichler A, Muerwald G, et al. Timing of peritoneal dialysis catheter removal after pediatric renal transplantation. Perit Dial Int 2001;21:467-70.

Correspondence: Dr. Tom McGregor, Department of Surgery, St-Boniface General Hospital, Z3032409 Tache Ave., Winnipeg, MB R2H 2A6; tom8mc@hotmail.com 